\title{
Study on Spheroidization and Related Heat Treatments of Medium Carbon Alloy Steels
}

\author{
Harisha S. R..$^{*}$, Sathyashankara Sharma ${ }^{1}$, U. Achutha Kini ${ }^{1}$ and Gowri Shankar M. C. ${ }^{1}$ \\ ${ }^{1}$ Department of Mechanical and Manufacturing Engineering, Manipal Institute of Technology, \\ Manipal Academy of Higher Education, Manipal, Karnataka 576104, India
}

\begin{abstract}
The importance of medium carbon steels as engineering materials is reflected by the fact that out of the vast majority of engineering grade ferrous alloys available and used in the market today, a large proportion of them are from the family of medium carbon steels. Typically medium carbon steels have a carbon range of 0.25 to $0.65 \%$ by weight, and a manganese content ranging from 0.060 to $1.65 \%$ by weight. Medium carbon steels are more resistive to cutting, welding and forming as compared to low carbon steels. From the last two decades a number of research scholars reported the use of verity of heat treatments to tailor the properties of medium carbon steels. Spheroidizing is the novel industrial heat treatment employed to improve formability and machinability of medium/high carbon low alloy steels. This exclusive study covers procedure, the effects and possible outcomes of various heat treatments on medium carbon steels. In the present work, other related heat treatments like annealing and special treatments for property alterations which serve as pretreatments for spheroidizing are also reviewed. Medium carbon steels with property alterations by various heat treatment processes are finding increased responsiveness in transportation, aerospace, space, underwater along with other variegated fields. Improved tribological and mechanical properties consisting of impact resistance, stiffness, abrasion and strength are the main reasons for the increased attention of these steels in various industries. In the present scenario for the consolidation of important aspects of various heat treatments and effects on mechanical properties of medium carbons steel, a review of different research papers has been attempted. This review may be used as a guide to provide practical data for heat treatment industry, especially as a tool to enhance workability and tool life.
\end{abstract}

Keywords: Medium Carbon Steel, Heat Treatment, Spheroidizing, Microstructure, Annealing

\section{Introduction}

Medium-carbon steels have carbon content ranging from 0.25 to $0.65 \%$ by weight. These categories of steels respond intensely to heat treatment processes, with wide variation in the mechanical and thermal properties. Depending on their response to heat treatment, they are

\footnotetext{
*Corresponding author: harisha.sr@manipal.edu
} 
divided into 2 categories. The first group containing carbon from 0.25 to $0.35 \%$ by weight, whereas the second group from 0.35 to $0.65 \%$ by weight. The second group response towards heat treatment is better, while of the first group is poor. That is why steels of the first group are suitable for moderately stressed components like, railway couplings, driving rings, hand tools, sockets and levers, tubes for bicycles, automobiles and aircrafts. Due to higher carbon content, 2nd group steels have more strength. Hence, they are used in high load applications, like spindles of machine tools, gears, bolts, cylinder liners, crank shafts, ball mill balls, etc. Typical medium carbon steels generally exhibit poor cold workability. It is widely known that their ductility can be improved significantly by spheroidization process. In 1970, a decisive major dynamic change was observed with the development of micro-alloyed medium carbon steels. Then, micro-alloyed steels containing $\mathrm{Cr}, \mathrm{Ni}, \mathrm{V}, \mathrm{W}$ etc. as refractory metals proved to be highly cost effective by attaining superior properties with least heat treatment processing cost [1]. The excellent toughness with high tensile strength is possible due to the addition of $\mathrm{Mn}$ and $\mathrm{Si}$ followed by reduction in carbon content [2].

\section{Spheroidization}

\subsection{Spheroidization of Medium Carbon Steels [3, 22, 28]}

Spheroidization experiments on AISI 4037 steel were performed, using inter-critical and sub-critical annealing. The results show that in sub-critical heating cycle, the spheroidization process has occurred faster than inter-critical annealing. So shorter times are enough to produce high formability. The other result was that in the inter-critical cycle the hardness dropped faster. In the testing of AISI 4037 steel $(0.37 \mathrm{C}, 0.80 \mathrm{Mn}, 0.22 \mathrm{Si}$, $0.25 \mathrm{Mo}$ by $\mathrm{wt} . \%$ ) rods of $3 / 8$ inches, the rate of spheroidization with inter-critical and subcritical cycles were compared. In inter-critical cycle, specimen was heated to $748^{\circ} \mathrm{C}$ for 2 hours, slowly cooled to $704^{\circ} \mathrm{C}$ followed by isothermal holding for 10 hours and later cooled at $5^{\circ} \mathrm{C} / \mathrm{min}$ approximately to room temperature. In the sub-critical cycle, the specimen was heated to $704^{\circ} \mathrm{C}$ for up to 10 hours and then cooled at approximately $5^{\circ} \mathrm{C}$ per minute.

To examine the microstructures developed, scanning electron microscopy (SEM) was used at each stage. After 4 and 12 hours of processing the surface was examined. They show that after 4 hours, in the sub-critical cycle, spheroidization was nearly complete whereas in the inter-critical cycle still un-spheroidized coarse pearlite was observed. It showed that the inter-critical cycle produces a much coarser spheroidised structure.

The more rapid rate of spheroidization during the subcritical process was attributable to the fact that a much finer pearlite was being spheroidized. With rapid spheroidization rate, high formability was the result of sub-critical route.

\subsection{Spheroidization Cycles for Medium Carbon Steels [4, 29]}

Two process cycles were considered in the spheroidization of medium carbon steels which are used in the temporary fastener industry. In the inter-critical cycle, the material was heated above the $A_{C 1}$ for 2 hours. The specimens were then allowed to cool below $A_{C 1}$ and were held there for various time intervals. This allowed the transformation of austenite and spheroidization of carbides. The second process was a sub-critical cycle. In this cycle the specimens were heated to temperature below the $A_{C 1}$ for different time periods. Two steels were studied in the process. Wires of AISI 1541 (high in manganese content and mild 
supporter of spheroidization) and AISI 4037 (prone to spheroidization, used extensively in fastener applications) were taken into consideration.

Similar drops in hardness were observed in both the cycles. But, 1 hour of the subcritical cycle produced higher ductility than 32 hours of the inter-critical process. The formability test also showed that spheroidization was faster in the sub-critical cycle. It was concluded that degree of formability is directly proportional to degree of spheroidization but not with changes in hardness due to alloying elements. Less time was required for spheroidization with sub-critical process than the inter-critical process.

\subsection{Sub-critical Spheroidization of Medium Carbon 50CrV4 Steel [5]}

Tests on sub-critical spheroidization annealing of cold rolled specimens were carried out on $50 \mathrm{CrV} 4$ steel at $720^{\circ} \mathrm{C}$. The chemical composition of $50 \mathrm{CrV} 4$ steel was $0.543 \mathrm{C}, 0.827 \mathrm{Mn}$, $0.23 \mathrm{Si}, 0.137 \mathrm{~V}, 1.012 \mathrm{Cr}, 0.019 \mathrm{Al}, 0.001 \mathrm{~S}$ and $0.011 \mathrm{P}$ by wt.\%. The $\mathrm{A}_{\mathrm{C} 1}$ of the steel is $740^{\circ} \mathrm{C}$ and the $\mathrm{A}_{\mathrm{C} 3}$ is $790^{\circ} \mathrm{C}$. Steel sheets were cut into specimens with $300 \times 200 \mathrm{~mm}^{2}$ rectangular dimensions. They were then annealed sub-critically at temperature of $720^{\circ} \mathrm{C}$ and furnace cooled at the rate of $10^{\circ} \mathrm{C}$ per minute to room temperature.

Tests showed that deformation with cold rolling accelerates the development of spheroidal cementite particles in the steel. If the deformation is high, the spheroidization occurs faster. Strength of the steel was decreased with respect to soaking time initially, but it had little effect on the hardness and the strength after 8 hours of spheroidization.

\subsection{Effect of Si on the Low Temperature Thermo-Mechanical Deformation and Spheroidization of Medium Carbon Steels [6, 31]}

Medium carbon steels SWRCH 45F, with composition 0.45 C, $0.35 \mathrm{Mn}, 0.03 \mathrm{Cr}$ and 0.2, $0.5,0.8,1.5 \mathrm{Si} \%$ by weight were subjected to heat treatment and deformed at elevated temperatures using Thermecmaster-Z. Rod specimens $8 \mathrm{~mm}$ in diameter and $12 \mathrm{~mm}$ in height were kept in the austenite region at a temperature of $950^{\circ} \mathrm{C}$ for $10 \mathrm{~min}$ and deformed under compression at $750,700,650$, and $600^{\circ} \mathrm{C}$, respectively, at a strain rate of $10 \mu \mathrm{m} / \mathrm{s}$, followed by controlled cooling at a rate of $10^{\circ} \mathrm{C} / \mathrm{s}$. The specimens were subjected to spheroidization at $730^{\circ} \mathrm{C}$ for $30 \mathrm{~min}$ and $3 \mathrm{~h}$, respectively, and subsequently underwent slow cooling with a cooling rate of $25^{\circ} \mathrm{C} / \mathrm{h}$ down to $680^{\circ} \mathrm{C}$, followed by air cooling. At the central region of the specimen microstructural characterization was performed as it is the region where the most severe plastic deformation is expected to take place. The average grain size and fraction of the ferrite were measured using a method specified in JIS standard G-0552 and an image analyzer, respectively. Electron microscopy was used to characterize the microstructures of the spheroidized specimens. The dilatometric change of the specimen was measured during heating $\left(0.08^{\circ} \mathrm{C} / \mathrm{s}\right)$ and cooling $\left(5^{\circ} \mathrm{C} / \mathrm{s}\right)$ using a Thermecmaster- $\mathrm{Z}$ to investigate the change in the transformation temperatures $\left(\mathrm{Ac}_{3}, \mathrm{Ac}_{1}\right.$ for heating and $\mathrm{Ar}_{3}, \mathrm{Ar}_{1}$ for cooling) with varying Si content.

With increasing Si content the transformation temperatures increased. Average fraction of the ferrite and grain size after thermo-mechanical deformation was also observed to increase with high Si composition. Addition of Si in low temperature thermo-mechanically processed medium carbon steels led to the required extent of spheroidization. A modified thermomechanical deformation and spheroidization heat treatment process was proposed and found to be highly applicable to Si added medium carbon steels. 


\subsection{Influence of Spheroidizing Heat Treatment on Mechanical Properties of EN 47 steel [7,20-21]}

The specific grade of medium carbon steel used to carry out the experiment was EN47 which is used widely in the formation of axles, gears etc. Heat treatment plan consisted of primary heating to a temperature of $815^{\circ} \mathrm{C}$ for a soaking time of 2 hours which is immediately followed by transfer of specimens to another furnace maintained at $750^{\circ} \mathrm{C}$ where the specimens are isothermally heated for different durations of time. The specimens are divided into three categories with 3 hours being the spheroidizing time for first set, 6 hours for second set and 9 hours for the third set of specimens. Mechanical tests carried out on the heat treated specimens were hardness, tensile, impact, wear and microstructure analysis. The microstructural analysis revealed the morphological change within the carbide phase with reference to the duration of processing. Spheroidal wearing was observed with heat treatment process increased beyond critical value. It was observed that with increase in treatment duration from 3 to 9 hours, the hardness of the material decreased continuously. With respect to the impact and tensile strength tests, it was observed that the strength showed an initial increase with increase in time of spheroidization, reached a peak and then decreased with further increase in processing time. Coefficient of friction values showed a decrease in their magnitude as the spheroidization processing time increased along with increase in wear resistance.

\section{Annealing}

\subsection{A New Approach for Rapid Annealing of Medium Carbon Steels [8, 34]}

The $42 \mathrm{CrMo}$ medium carbon steel was the primary material used in the test. $20 \times 10 \times 2$ $\mathrm{mm}^{3}$ dimensioned cuboidal specimens were obtained from the hot rolled rod, with the hot rolling direction being in parallel with the longitudinal direction. $15 \mathrm{~T}$ cryo-cooled superconducting magnet, $52 \mathrm{~mm}$ in bore size was used with a furnace set in it to perform magnetic annealing, where the central (zero magnetic force) region was used for positioning and placement of specimens with magnetic field direction made parallel to the direction of hot rolling. Specimens were heated to $880^{\circ} \mathrm{C}$ and soaked for 33 min with a subsequent $46^{\circ} \mathrm{C} / \mathrm{min}$ cooling rate along with a $14 \mathrm{~T}$ magnitude magnetic field. Conventional full annealing consisted of heating at $860^{\circ} \mathrm{C}$ with soaking time of $30 \mathrm{~min}$ in a chamber furnace of ordinary type followed by furnace cooling with a cooling rate of $1{ }^{\circ} \mathrm{C} / \mathrm{min}$. Post and pre heat treated specimens were subjected to etching. An optical microscope equipped with image analyzer was used for microstructural examination. Vicker's micro-hardness test was performed with a $5 \mathrm{kgf}$ load. In $42 \mathrm{CrMo}$ steel banded structure formation initiated due to preferential nucleation of pro-eutectoid ferrite within fine grained zones of hot rolled microstructure along the austenite grain boundaries. Uniform and fine microstructure of pearlitic colonies along with ferrite grains was produced using the dual strategy of $46^{\circ} \mathrm{C} / \mathrm{min}$ high cooling rate and high magnetic field of magnitude 14T.

\subsection{Formation of medium carbon TRIP steel microstructure during annealing in the inter-critical temperature range $[9,17-18]$}

Mechanically unstable retained austenite along with multiphase microstructure are the primary characteristics of Transformation Induced Plasticity (TRIP) steels. TRIP steel (41MnSi6-5) was subjected to dilatometric tests which comprised the initial stage of 
experiments. Through a heating rate of $3^{\circ} \mathrm{C} / \mathrm{min}, 2 \times 12 \mathrm{~mm}^{2}$ sized samples were heated till $1200^{\circ} \mathrm{C}$ in dilatometer DT1000. Sample relative elongation L/Lo was recorded as a function of temperature $\mathrm{T}$ while heating. Predetermined inter-critical temperatures range of $730-870^{\circ} \mathrm{C}$ was used for a time duration of $30 \mathrm{~min}$ within which the samples of size $12 \times 10 \times 10 \mathrm{~mm}^{3}$ were heated. Martensite was obtained through transformation from austenite because of water quenching. Metallographic micro-sections were subjected to Xray quantitative phase analysis which was used to assess the retained austenite volume fraction. X-ray diffractometer TuR-M61 was used for these tests through the application of filtered cobalt radiation immediately after X-ray tests for the purpose of revealing structural components. $2 \%$ Nital was used to etch the samples for revealing the microstructure. Revealed microstructure characterization was conducted through scanning microscope FEI Nova Nano SEM 450 and Light microscope Axiovert 200MAT. Point-count and lattice variant quantitative metallography methods of manual nature were used on the visible microstructural components to obtain the volume fractions. Heat treated samples were subjected to Vickers hardness test at $30 \mathrm{~kg}$ load. At a load of $10 \mathrm{~g}$ the Knoop indenter was used for the $750^{\circ} \mathrm{C}$ annealed sample for verification of identified microstructural components. Largest volume fraction of retained austenite was obtained within the microstructure of samples annealed at low temperatures in the inter-critical range. It was observed that contrary to common notion of differential transformation of ferrite to low carbon austenite, the transformation actually runs simultaneously. For applications of final retained austenite volume fraction and increased carbon content in austenite in the TRIP steel microstructure, the strategy to be followed is to go for the modification which would allow to lower the annealing temperature range to $\mathrm{Ac}_{1}+\max .30^{\circ} \mathrm{C}$.

\section{Unconventional Heat Treatments}

\subsection{Effect of Post Weld Heat Treatment on the Mechanical Characterization of Medium Carbon Steel Weld [10, 23-24, 30, 32]}

Mechanical properties of weld in $0.36 \% \mathrm{C}$ medium carbon steel was analyzed. Post weld heat treatment (stress relief) was done on welded samples at four different sub-critical temperatures $550,600,650$ and $700^{\circ} \mathrm{C}$ followed by air cooling. The welding process used is SMAW with low hydrogen electrode (E7018) at a current of 130 A. Hardness and tensile tests were done on the samples later. The percentage loss in strength due to post weld heat treatment (PWHT) at the above temperatures followed by air cooling was 10.8, 12.2, 15.1 and $13.1 \%$ respectively. The best PWHT temperature for the property improvement of medium carbon steel is $650^{\circ} \mathrm{C}$ and the corresponding loss in strength was about $15.1 \%$.

\subsection{Some Laser Treatments Effects on Medium Carbon Steels [11]}

Austenization and oil quenching were applied on plates $10 \mathrm{~mm}$ thick of $0.38 \mathrm{wt} . \% \mathrm{C}-\mathrm{Ni}-\mathrm{Cr}$ Mo low alloy $(0.4 \mathrm{wt} . \% \mathrm{C})$ alloy steel. The plates were graphite coated to increase absorptivity and subjected to single pass laser irradiation. The beam translation speeds were 8.3 and $5.0 \mathrm{~mm} / \mathrm{s}$ along with a beam size of $10 \times 10 \mathrm{~mm}^{2}$. Corresponding interaction times of laser material were 1.2 and $2.0 \mathrm{~s}$ and the incident power densities were 2.1 and 2.6 $\mathrm{kW} / \mathrm{cm}^{2}$ and along with energy densities of 25 and $52 \mathrm{MJ} / \mathrm{m}^{2}$. The Mossbauer measurements were performed at room temperature using a $40 \mathrm{~m} \mathrm{Ci} 57 \mathrm{co}(\mathrm{Rh})$ source, and by detecting the re-emitted $6.4 \mathrm{keV} \mathrm{X}$-rays and the $7.3 \mathrm{keV} \mathrm{K}$-shell conversion electrons. Computer-controlled goniometer and CoKo radiation were used for X-ray diffraction analyses. Scanning electron microscopy and optical microscopy were utilized for the 
examination of the cross sections for the treated samples. A critical stage for laser treatments of steels is the control of the atmosphere composition. Irrespective of the use of a helium stream and graphite coating, all the treated samples underwent surface oxidation phenomena. Formation of low carbon phases is promoted under strongly oxidizing conditions and surface melting is hindered or prevented. Composition of the steel under laser processing conditions varying in the neighborhood of incipient melting has major influence on the extent to which melting takes place.

\subsection{Influence of Heating Rate to Austenitic State on the Laser Surface hardening of a Medium Carbon Steel [12, 27, 33]}

Specimens of $5 \mathrm{~mm}$ thickness medium carbon steel (SM 45C) was laser surface hardened at varying traverse speeds and beam spot diameters. Composition consisted of $0.26 \mathrm{Si}, 0.73$ $\mathrm{Mn}, 0.013 \mathrm{P}, 0.005 \mathrm{~S}$ and $0.45 \mathrm{C}$ by wt.\%. For uniformity in conditions of absorption, before each hardening process surface of the specimen was cleaned and ground thoroughly. A $1 \mathrm{~kW} \mathrm{CO} 2$ laser system was used to perform surface hardening with varying traverse speeds of $0.5-3 \mathrm{~m} / \mathrm{min}$ along with beam spot diameters ranging from $1.6-3.5 \mathrm{~mm}$. Normal to the translation direction cutting was done of the processed specimens for metallographic examination. Through micro hardness testing and use of normal etching methods, a $100 \mathrm{gf}$ load was used with a diamond pyramid indenter in the hardened zones. The theoretical result by Bramson's or Arata's equation and adopted for the FDM simulation to global absorptivity levels $15 \%$ less than that measured using a calorimeter. According to the distance of the work piece surface from the focal point for comparison of calculated and experimental results the critical beam spot diameter must be determined. The average diameter at which the beam average intensity falls to $5 \%$ of the maximum beam intensity was defined as the beam spot diameter. Through comparison of the burned zone widths produced on the acrylic plate under various defocused distances and traverse speeds, the relationship between the defocused distance and the beam spot diameter was determined. The criteria for choosing beam spot diameter were such that at the boundary of the burned zone the total incidence energy per unit area remained constant irrespective of irradiation conditions. Between the beam spot diameter $D_{b}$ and the defocused distance $f_{d}$, the mathematical relationship could be expressed as

$$
\mathrm{D}_{\mathrm{b}}=\mathrm{A} \exp \left(\mathrm{Bf}_{\mathrm{d}}\right)
$$

Where B and A are constants which are obtained using method of least square. To account for the shift in the austenitic transformation temperature the temperature dependent specific heat was modified, the specific heat in the solidification range was modified as follows taking latent heat into account

$$
\mathrm{C}_{\mathrm{m}}=\frac{\mathrm{C}_{\mathrm{g}}+\mathrm{C}_{\mathrm{l}}}{2}+\frac{\mathrm{H}}{\Delta \mathrm{T}_{\mathrm{lg}}}
$$

where $C_{l}$ and $C_{S}$ represent specific heats at the liquidus and solidus temperature respectively, $\Delta T_{\mathbb{I s}}$ is the temperature difference between the solidus and liquidus temperature whereas $H$ is the latent heat of fusion. Resistivity measurements or Dilatometer showed that heating rate strongly influences transformation behavior in steels.

For analysis of laser transformation hardening the finite difference method is pretty accurate. While determining isothermal lines for hardening the effect of forced convection was negligible. The calculated size and shapes of hardened zone correlated well with those 
obtained by experiment with the modified transformation temperatures. For accuracy in predicting the laser surface hardening zone, the relationship between the machine and beam spot diameter setting has to be analyzed. At the surface width of the hardened zone increases with increasing beam spot diameter at relatively small beam spot diameters. For a given laser power input and traverse speed there can be a range of beam spot diameters which without any surface melting produce a large width of the hardened zone.

\section{Property Alterations in Heat Treatment Processes}

\subsection{The Microstructural Influence on the Mechanical Behavior of Medium Carbon Steel after Heat Treatment $[13,19]$}

Unalloyed carbon EN8 steel in the form of rolling bar was the test specimen used in this investigation. Tensile specimens were machined to standard dimensions and prepared using heat treatment experiments. Dimensions of ASTM standard were used to prepare tensile strength test specimens to be subjected to heat treatment cycles. Four sets of "A", "B", "C" and " $\mathrm{D}$ " groupings were made for tensile test. Microstructure characterization and phase identification of samples was obtained using Optical Electronic Microscope (OEM) and Scanning Electron Microscopy (SEM). Type, shape and size of granular structure were the principal properties to be examined of the test specimens. Hardness and tensile strength tests were primarily used for mechanical characterization of specimens. Four heat treatment plans were used for four specimens. The first one consisted of $950^{\circ} \mathrm{C}$ austenitizing soaked for $180 \mathrm{~min}$ with furnace cooling, second one consisted of $914^{\circ} \mathrm{C}$ austenitizing soaked for $10 \mathrm{~min}$, with furnace cooling to $680^{\circ} \mathrm{C}$, third heat treatment plan comprised of austenising at $914^{\circ} \mathrm{C}$, held for $10 \mathrm{~min}$, cooled in furnace and fourth heat treatment plan comprised of austenitizing at $914^{\circ} \mathrm{C}$ soaked for $3 \mathrm{~min}$ with furnace cooling to $715^{\circ} \mathrm{C}$ and subsequent oil quenching. Five different microstructures were obtained through the heat treatment cycles. Heavy impact on the characteristics of yielding was attributed to distribution and size of grain. For variable grain size distribution in a multiphase structure, high Von Mises stress was experienced in stronger phase while weaker phase was characterized by high plastic deformation. Distribution and grain size were profoundly impacted by holding time and annealing temperature. Increased formation of second phases (bainite and martensite) upon cooling and grain coarsening were promoted with increase in soaking time and annealing temperature. Material flow dependent manufacturing processes would be benefited through the "B" sample heat treatment because of coarse grains as yield strength increased linearly with decreasing grain size in conventional materials. "C" and " $\mathrm{D}$ " heat treatments would be appropriate for high hardness and high strength applications.

\subsection{Effect of Thermal Treatment on the Bauschinger Effect for a Medium Carbon Steel $[14,25]$}

The steel used for this heat treatment process was DIN Ck60. The material was first hotrolled, then normalized at $800^{\circ} \mathrm{C}$ for an hour and was cooled in the furnace. Then machined in the shape of button-head push-pull with a diameter of $14 \mathrm{~mm}$. A $250 \mathrm{kN}$ MTS testing machine was used to perform loading for all specimens. At room temperature, they were strained at $5 \times 10^{-4} \mathrm{~S}^{-1}$ strain rate. The load versus displacement curves were obtained after measuring the strains using a longitudinal extensometer $25 \mathrm{~mm}$ in gauge length. In the initial condition, a pre-strain of $2.5 \%$ of total true strain in the mode of tension was applied on the specimens. The next process occurred over an hour where the specimen pairs were heated at temperatures from $373-873 \mathrm{~K}$. Then each pair was reloaded one in compression 
and the other in tension. Loading in compression was limited to $1.5 \%$ total true strain, to not cause buckling. The chemical composition of the steel used is of $0.26 \mathrm{Si}, 0.55 \mathrm{Mn}$, $0.021 \mathrm{P}, 0.032 \mathrm{~S}$ and $0.66 \mathrm{C}$ by wt.\%.

Heating medium carbon steel above $0.25 \mathrm{~T}_{\mathrm{m}}$ (where $\mathrm{T}_{\mathrm{m}}$ is the melting point) reduces the Bauschinger effect. This is because of a recovery annealing assisted by short-range recoverable internal stresses. To determine the Bauschinger effect, the altered value of mechanical properties in the pre-straining direction should also be taken into consideration. It was observed that strain does not influence the Bauschinger effect.

\subsection{Behavior of Medium Carbon Steel under Combined Fatigue and Wear [15, 26]}

The choice of material for this experiment was AISI 1045. A cylindrical shape of $16 \mathrm{~mm}$ ( $5 / 8$ in) in diameter was given to the material. To provide accurate shape to the testing region, a lathe tool of $12.7 \mathrm{~mm}$ radius was used. Emery paper was used to polish the necked area to a minimum diameter of $6.4 \mathrm{~mm}$, followed by $6 \mu \mathrm{m}$ particle size lapping compound embedded with diamond lap for finishing. A thin film of cadmium $(0.1 \mu \mathrm{m})$ or nickel $(0.05$ $\mu \mathrm{m})$ was used for plating on few specimens. A layer of gold $(0.5 \mu \mathrm{m})$ was then applied on them. Then, lathe was used for combined fatigue wear tests and fatigue. The configuration of the load applied at the end of a cantilever rotating beam was adopted. Dead weights of $0.3 \mathrm{~kg}$ were applied as the normal load as well as fatigue load on the slider. A strain gage assembly with a slider attached to it was used to measure the force of friction. Argon atmosphere and air were used as the medium of tests. To have a controlled atmosphere to perform the tests, the slider and specimen were enclosed in a chamber, which was completely vacuumed out and then filled with argon gas. The tests were performed continuously until the specimen failed at an rpm of 1000. As the load on the slider was gradually increased, the rate of crack nucleation at the surface also enhanced and a doubling was observed in the actual number of fatigue loading cycles. The coating on the specimens reduced the wear rate, but it does not enhance the fatigue.

\subsection{The Effect of Quenching on the Wear Rate of Medium Carbon Steel [16]}

This experiment was conducted on a " $\Phi \mathrm{K}$ " type fretting tester. The load was applied using a weighted lever and the contact pressure was calculated from the calculated contact area of the specimens. The conditions of operation for this machine were amplitude range of 20 to $1000 \mu \mathrm{m}$, frequency between $1.86-25 \mathrm{~Hz}$ and contact pressures of $5.3-110 \mathrm{MN} \mathrm{m}^{-2}$.

Commercial cylindrical $45 \mathrm{~mm}$ diameter carbon steel, with annular contact surfaces, was used for this experiment. A few of the specimen pieces were made to undergo quench hardening up to $587 \mathrm{HV}$. They were marked H45. Before starting the wear test, surfaces undergoing the test of every specimen was finished by grinding to get a rough state of grade $0.32-0.63 \mu \mathrm{m} R_{a}$,

Before the testing, the specimens were weighed to know their initial weight. After the test, they were weighed again, to know the weight loss. To obtain the cumulative reduction in mass, the waste material filaments were collected and weighed from time to time. Inert gas fusion oxygen determining machine was used to gather data about the percentage oxygen present in the shavings obtained after the test.

After that on the annular surfaces, a couple of cuts were made and along with that the $\mathrm{NiCr}-\mathrm{NiAl}$ thermocouples of $\Phi 0.5 \mathrm{~mm}$ were embedded in the specimen. A twin pen recorder was kept to note down the temperature rise from time to time. The entire experimental setup was put up at room temperature conditions. Quench hardening of carbon steel had a lot advantages. It enhances fatigue strength, tool life and hardness. 


\section{Summary}

The extensive literature survey presented above portrays the effects of spheroidization, annealing and related heat treatment processes on various grades of medium carbon alloy steels under differing conditions of heat treatment process parameters. While it was observed that spheroidization was accompanied by good cold workability and formability characteristics and annealing showed a marked increase in the percentage of fine grained pearlitic structure; further in depth analysis has to be done to obtain better quantitative results. Along with the conventional heat treatment processes like annealing and spheroidization, this paper also delves into the realm of certain unconventional processes like post weld and laser heat treatments which have not been adopted at an industrial scale and thus holds great research and commercial potential in the near future. Material science researchers at all levels will find this review on medium carbon steels helpful in their own scientific pursuits.

\section{References}

1. T. Gladman, D. Dulieu, I. D. McIvor, Microalloying 75 symposium (Washington DC, 1977)

2. S. Sankaran, V. S. Sarma, K. A. Padmanabhan, Mater Sci. Engg., A345, 328 (2003)

3. J. M. O’Brien, W.F. Hosford, J. of Mat. Eng. Per. 6, (1997)

4. J. M. O’Brien, W.F. Hosford, Met. Mat. Tran A 33A, (2002)

5. W. Y. Guo, J. Li, X. F. Jiang, J. of Mat. Eng. Per. 21, (2012)

6. Y. S. Choi, I.M. Park, J.H. Kim, K.M. Cho, D.L. Lee, Met. Mat. Int. 11, 327 (2005)

7. S.R Harisha, S.S. Sharma, U. A. Kini, Mat. Sci. For. 880, 136 (2016)

8. Y. Zhang, C. He, X. Zhao, C. Esling, L. Zuo, Adv. Eng. Mat. 6, 5 (2004)

9. A. Kokosza, J. Pacyna, Arch. Met. and Mat. 59, 3 (2014).

10. S. M. Manladan, B. O. Onyekpe, App. Mech. Mat. 315, 6 (2013)

11. M. Carbucicchio, G. Sambogna, G. Palombarini, Hy. Int. 28, 1021 (1986)

12. S. J. NA, Y. S. Yang, Sur. Coat. Tech. 34, 319 (1988)

13. K.O. Sansui, C.M. Moleejane, O.L. Ayodele, G.J. Oliver, Tran. Eng. Tech. 525 (2015)

14. Aran, M. Demirkol, Mat. Sci. Eng. 47, 89 (1981)

15. T. Nagao, J.J. Pamies-Teixeira, Wear 44, 101 (1977)

16. D. X. lin, Wear 123, 77 (1988)

17. A. Bhateja, A. Verma, A. Kashyap, B. Singh, I. J. of Eng. Sci. 1, 253 (2012)

18. A. Saha, D. K. Mondal, J. Maity, Mat. Sci. Eng. A, 537, 4001 (2010)

19. Sarwar M, Priestner R., J. of Mat. Sci. 31, 2091-2095. (1996),

20. A. Saha, D. K. Mondal, J. Maity, Mat. Sci. Eng. A, 537, 4001 (2010)

21. J. Y. Li, S. Suguyama, J. Yanagimoto, Y. L. Chen, G. W. Fan, J. Mat. Pro. Tech. 208, 165 (2007)

22. S. Y. Oh, I.H. Son, K.H. Jung, D.K. Kim, D.L. Lee, Y.T. Im, Mat. Sci. Eng. 528, 5833 (2011)

23. Y. W. Lee, Y. Son, S. J. Lee, Mat. Sci. Eng. A, 585, 94 (2013)

24. A. J. Abdalla, L. R. O. Hein, M. S. Pereira, T. M. Hashimoto, Mat. Sci. Tech. 15, 1167 (1999) 
25. S. Sun, M. Pugh, Mat. Sci. Eng, 335, 298 (2002)

26. M. Erdogan, R. Priestner, J. Mat. Sci. Tech. 18, 369 (2002)

27. H. Goto, Y. Amamoto, Wear 254, 125 6(2003)

28. D. H. L. Ng, K. S. Cho, M. L. Wong, S. L. I. Chan, Mat. Sci. Eng 358, 186 (2003)

29. P. K. Mitra, S. Paul, S. Chatterje, J. Mat. Mat, 85, 78 (2004)

30. Y. Zia, W. Liu, Q. Xue, Wear, 38, 508 (2005).

31. S. M. Anijdan, H. Vahdan, Mat. Let. 59, 1828 (2005)

32. P. Larour, P. Verleysen, W. Bleck, J. Phy. 134, 1085 (2006)

33. P. L. Menezes, Kishore, S. V. Kailas, Wear 261,578 (2006)

34. A. P. Modi, Tri. Int. 40, 490 (2007)

35. M. Sarwar, E. Ahmad, K. A. Qureshi, Manzoor, Mat. Des, 28, 335 (2007) 